Gladius XXV, 2005, pp. 187-206

\title{
ARQUEOZOOLOGÍA DEL CABALLO EN LA ANTIGUA IBERIA
}

POR

\author{
CORINA LIESAU VON LETTOW-VORBECK
}

\begin{abstract}
RESUMEN - ABSTRACT
Una de las especies que mayores controversias ha suscitado desde su proceso de domesticación hasta el comienzo de los variados usos a los que ha sido sometida es el caballo. Sin ánimos de exponer más allá de una breve síntesis alguno de los debates en curso, tratamos las principales evidencias directas e indirectas que han servido para abordar su proceso de domesticación y las dificultades a las que se enfrenta la Arqueozoología en el estudio de las limitadas muestras óseas del registro arqueológico, especialmente en las etapas de la Prehistoria más reciente. Aunque la funcionalidad de esta especie resulta en muchos contextos problemática se confirma en algunos casos como un recurso alimentario de primer orden, además de su empleo como animal de tiro, monta y carga. En menor medida, el caballo también está vinculado a depósitos relacionados con el mundo funerario y simbólico, cuyas exiguas evidencias directas contrastan con el rico patrimonio arqueológico y su sobrerrepresentación literaria de las etapas prerromanas.
\end{abstract}

The horse is one of the species that greater controversies stir up since its process of domestication to the beginning of the different known uses. Although in this synthesis our aim is not to emphasize all the debates, we try to discuss some of the direct and indirect evidences as proof of horse domestication and husbandry and the difficulties and limitations that the archaeozoological studies affront with a generally scarce available faunal record, especially in the recent prehistoric times. Although the functionality of this species results in many cases problematic it is confirmed that in some sites there is a relevant consumption pattern, beside other uses as traction and riding. In some cases horse deposits are included in ritual or burial practises but these few evidences still contrast with the rich archaeological and overrepresented literary record in the Iberian Peninsula at the preroman times.

\section{PALABRAS CLAVE - KEY WORDS}

Caballo, Peninsula Ibérica, consumo, carga, tiro, monta, ritual.

Horse, Iberian Peninsula, consumption, pack, traction, riding, ritual.

El manejo y la cría del caballo durante la Prehistoria ha sido un tema ampliamente debatido en las últimas décadas, por lo que en este trabajo tan sólo queremos aportar algunos aspectos que nos parecen interesantes en torno las posibilidades y limitaciones que nos ofrecen los estudios arqueozoológicos realizados hasta la fecha.

No cabe duda de que el empleo de este animal ante el carro revolucionó el transporte de bienes y de personas. Su posibilidad de monta provocó además grandes avances en las tácticas militares y un buen control ecuestre podía ser determinante de cara el éxito en las batallas, convirtiendo al caballo, en un animal excepcional para la Humandidad (Benecke, 1994). Pero el camino hasta su manejo y domesticación fue muy largo, siendo una de las especies que más incógnitas presenta de cara a su domesticación y posterior raciación. Evidentemente, muchos aspectos desconocidos se deben a la propia naturaleza del registro arqueológico: 
predominan muestras en las que los restos de caballo son testimoniales, sus huesos como desechos alimentarios suelen estar muy fragmentados, y los criterios osteomorfológicos y métricos —a pesar de un nutrido colectivo de especialistas en la materia- no resultan siempre ser aplicables o fiables.

El comienzo de la domesticación del caballo es uno de los grandes caballos de batallanunca mejor dicho- de numerosos investigadores. Algunas hipótesis se remontan a períodos muy antiguos por una serie de evidencias plasmadas en el arte del Paleolítico Superior tales como representaciones y contornos recortados de cabezas equinas, portando supuestamente, arcaicos arneses con sogas o embocaduras, caballos con capas moteadas, así como posibles representaciones de cerramientos para el control de los équidos. Tampoco se ha descartado que determinados artefactos como una placa perforada de La Quina y algunos bastones perforados - formando parte de arneses - sirvan de elementos de control de los caballos. No faltan determinadas paleopatologías dentarias registradas en las muestras fósiles de La Quina y de Le Placard que en la actualidad se conocen en las formas domésticas. Se trata de desgastes anormales los incisivos que presentan muescas y biselados como resultado de un mordisqueo reiterado y que los veterinarios definen como vicios de establo (tiquage, crib-biting) (Bahn, 1978, 1980, 1984; Gautier, 1990, 1998).

Aunque investigadores como Gautier no descartan la posibilidad de un manejo aislado de algún caballo durante el Paleolítico, los argumentos en torno a las evidencias arqueológicas anteriormente expuestas no permiten asentar una base fiable para postular su domesticación e, incluso, paleopatologías dentarias idénticas a las anteriormente descritas se conocen en poblaciones de caballos del Pleistoceno inicial y medio en America del Norte siendo, por tanto, totalmente ajenas a posibles influencias antrópicas (Gautier, 1998). Otro argumento en contra del control o domesticación de los los caballos silvestres durante el Paleolítico es su extinción o drástica disminución en amplias áreas europeas a finales del Pleistoceno (Uerpmann, 1995; Olsen, 1998).

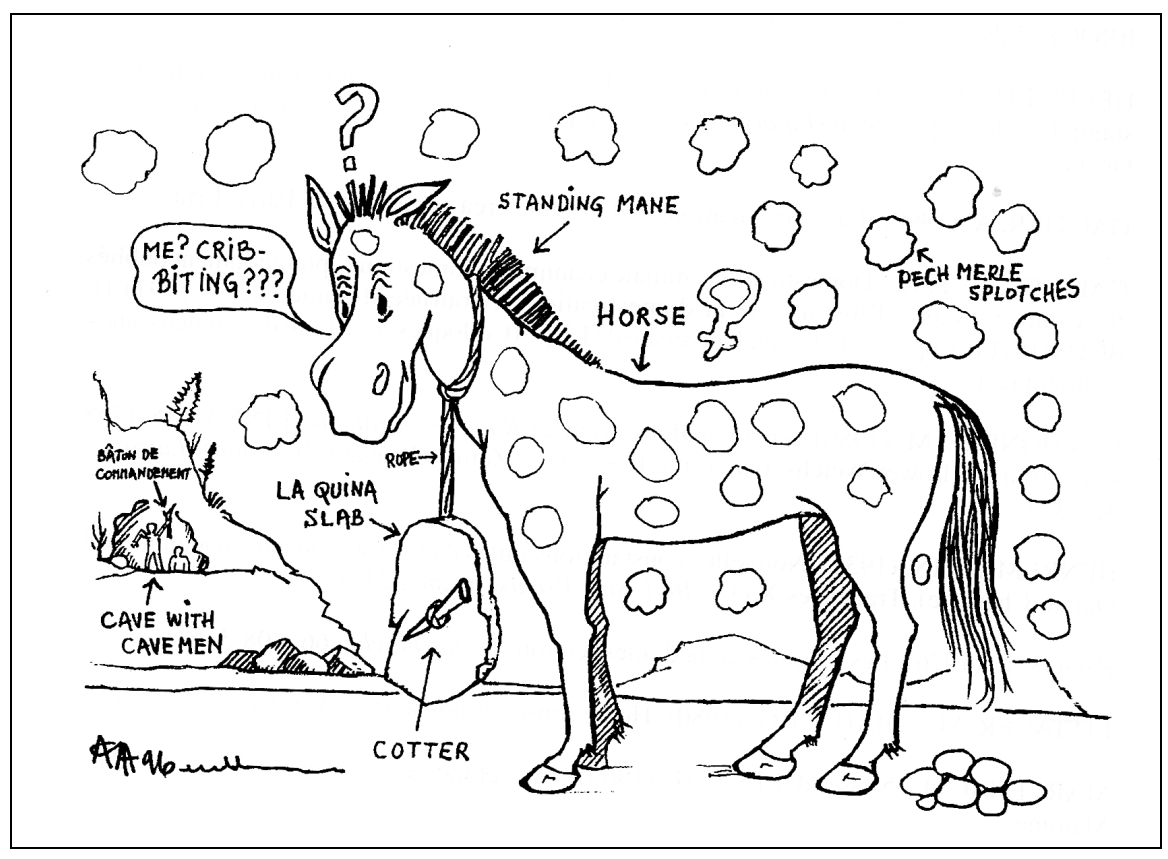

Fig. 1. Revisión crítica de la domesticación del caballo durante el Paleolítico según Gautier (1998:50). 
Para la Península Ibérica podemos constatar que los caballos silvestres son, junto con los ciervos, los ungulados más frecuentemente reflejados en el arte rupestre (Altuna, 2002). Sin embargo, esa fascinación y generosidad repesentativa en el arte no se refleja con la realidad arqueozoológica cuyo registro suele muy exiguo. En futuros hallazgos del Pleistoceno Final e inicios del Holoceno sería de sumo interés averiguar si aquellos yacimientos con elevadas frecuencias de huesos de équidos pueden estar relacionados con una incipiente domesticación del lobo. Sus descendientes caninos en vías de domesticación podrían iniciar, en colaboración con los grupos cazadores-recolectores, una nueva y exitosa estrategia de acoso y caza de caballo tal y como se argumentado para algunos yacimientos magdalenienses alemanes (Musil, 2000).

Parece que el ancestro directo, el tarpan (Equus ferus) se extinguió en las estepas ucranianas en el siglo XIX, quedando un superviviente silvestre asiático, el denominado Equus przewalskii. Aunque desgraciadamente tampoco se puede asegurar que éste último haya conservado intacta su pureza su linaje genético difiere obstensiblemente de nuestras formas domésticas (Eisenmann, 1998 Jansen et al., 2002). Sin embargo, las características reflejadas en el arte rupestre permiten en cierta medida comprobar algunos detalles que coinciden con el Przewalskii y la naturaleza de los équidos silvestres: constitución robusta, cabeza corta, cuello recio y ancho, crines erguidas que se mudan anualmente, capa larga durante el invierno y corta durante el verano, cola tupida, panza abultada, piernas cortas, raya dorsal y zebraduras en las patas. Estas últimas, la línea en «M» y la banda crucial debían presentarse en los caballos paleolíticos de la zona de la cueva de Ekain, como manifiestan Altuna y Apellaniz (1978), por citar tan sólo un ejemplo. Curiosamente algunos de estos caracteres se presentan aún hoy en día en caballos del SW peninsular denominados sorraianos. ¿Podrán en un futuro próximo los análisis genéticos esclarecer los orígenes de algunas formas domésticas sin descartar variantes asilvestradas que conservan caracteres arcaicos?

Pasando a valorar el aspecto de la domesticación del caballo en relación con otros ungulados, ésta se inicia en una etapa tardía dentro de la Prehistoria. Aunque evidentemente no podemos descartar la captura ocasional y manutención en cautividad de caballos silvestres, el proceso de la domesticación animal es complejo e implica una serie de cambios sobre una reducida población cuyo aporte alimentario y la reproducción son controlados por la comunidad humana (Bökonyi, 1987, Gautier, 1990; Bökonyi y Meid, 1993). En las últimas décadas se han investigado las consecuencias de la domesticación no sólo de cara a la osteomorfología, sino los cambios genéticos fisiológicos y etológicos, bien conocidos en otros mamíferos como los cánidos (Clutton-Brock, 1987, 1995; Crockford, 2000; Serpell, 1995).

Aunque los investigadores no se ponen de acuerdo sobre el inicio de la domesticación, las primeras evidencias estudiadas sobre grandes muestras de restos de tarpanes (Equus ferus) aparecen a finales del IV Milenio a.C. en diferentes ámbitos de las estepas euroasiáticas. En una serie de yacimientos del Neolítico Final y Eneolítico las proporciones de restos de caballos consumidos alcanzan elevados porcentajes. Serednij-Stog o Dereivka (Ukrania) son ejemplos en que se ha estudiado los perfiles de mortandad que coinciden con animales jóvenes-subadultos, sobre todo machos o también un aumento de la variabilidad osteométrica (Telegin, 1986). Este patrón se decanta claramente hacia un aprovechamiento cárnico, aunque para muchos yacimientos el estatus silvestre o doméstico de los caballos consumindos ha suscitado acalorados debates (Levine et al., 2003). También hubo intrusiones posteriores que sucitaron polémicas como el famoso depósito de un caballo con arreo y dos perros hallado en Dereivka (Anthony y Brown, 1991, 2003; Anthony et al., 1991, Levine, 1990).

Estudios recientes parecen postular un orígen multiple del caballo doméstico, en los que se incluyen otras áreas como Europa Central, y la Península Ibérica, aunque su rango cronológico no supera el III Milenio a.C. (Uerpmann, 1990, 1995; Benecke, 1994, 1999; Levine, 2004 y Jansen et al., 2002). 
Antes de entrar a valorar los restos de équidos en la Península Ibérica tendríamos que tener en cuenta algunas consideraciones:

En general, aunque las muestras de caballos silvestres no son muy grandes ni estadísticamente relevantes, parecen confirmarse algunas diferencias métricas y morfológicas entre las muestras paleolíticas con respecto a períodos posteriores (Altuna, 1972; Pérez Ripoll, 1977; Castaños 1986).

Como apuntan Morales et al. (1998), son ya antiguas las consideraciones sobre la posibilidad de que la Península Ibérica fuese un foco de domesticación autócotono. En esta línea, Uerpmann (1990) defiende también —en base a criterios osteométricos, es decir, reducción de talla y mayor variabilidad osteométrica - esa viabilidad a partir de la subespecie denominada Equus ferus lusitanicus.

Otra importante cuestión a tener en cuenta en el estudio de las muestras de équidos prehistóricos es la existencia de dos géneros silvestres en el ámbito peninsular, el caballo silvestre y el asno silvestre (Equus hydruntinus) (Boessneck, 1973; Uerpmann, 1976). Recientemente von den Driesch ha revisado algunos huesos inicialmente asignados a este asínido llegando a cuestionar la posibilidad de la supervivencia del hydruntinus más allá del III Milenio a.C. (Driesch, 2000).

En un estudio recopilatorio coordinado por el Prof. Arturo Morales realizamos un catálogo de los restos de équidos hallados en 138 yacimientos de la Península, abarcando ocupaciones del Epipaleolítico/Mesolítico hasta el Bronce Tardío (Morales et al., 1998). Los resultados han sido muy reveladores, pero no precisamente por la generosidad de los datos, sino por los exiguos restos hasta ahora recuperados. Destacan, por un lado, auténticas lagunas en la investigación, también en función de dónde se ubiquen geográficamente los especialistas, en este caso los equipos de arqueozoólogos. Los resultados dependen de la posibilidad e interés del estudio de los restos de fauna, del estado de investigación de las excavaciones y la demora en ser publicados numerosos informes inéditos, pero también problemas de investigación causados por condicionantes edáficos y tafonómicos impiden la conservación de material orgánico, caso del NW de la Península (Figura 2).

\begin{tabular}{|c|c|c|c|c|c|c|c|c|}
\hline & Epipaleolítico & $\begin{array}{l}\text { Epipaleo/ } \\
\text { Neolítico }\end{array}$ & $\begin{array}{l}\text { Neo } \\
\text { lítico }\end{array}$ & $\begin{array}{l}\text { Neolítico/ } \\
\text { Edad Cobre }\end{array}$ & $\begin{array}{l}\text { Edad } \\
\text { Cobre }\end{array}$ & $\begin{array}{l}\text { Edad Cobre/ } \\
\text { Edad Bronce }\end{array}$ & $\begin{array}{c}\text { Edad } \\
\text { Bronce }\end{array}$ & Total \\
\hline ANDALUCÍA & - & - & 2 & 4 & 6 & - & 10 & 22 \\
\hline ARAGÓN & 3 & - & 5 & - & - & - & 10 & 18 \\
\hline CAST.- LA MANCHA & - & - & 1 & - & 1 & - & 11 & 13 \\
\hline CASTILLA-LEÓN & - & - & - & 1 & 6 & - & 5 & 12 \\
\hline CATALUÑa & 2 & - & 4 & - & 1 & - & - & 7 \\
\hline EXTREMADURA & - & - & - & - & 3 & - & 2 & 5 \\
\hline LA RIOJA & - & - & 1 & - & - & - & 2 & 3 \\
\hline MADRID & - & - & - & - & 4 & - & & 4 \\
\hline MURCIA & - & - & 1 & - & 5 & - & 6 & 12 \\
\hline NAVARRA & 1 & - & 2 & - & 1 & - & 1 & 5 \\
\hline P. VALENCIANO & 8 & - & 9 & 1 & 2 & - & 5 & 25 \\
\hline P.VASCO & - & - & 5 & 1 & 5 & 1 & 1 & 13 \\
\hline PORTUGAL & 2 & 2 & 1 & - & 17 & - & - & 22 \\
\hline TOTAL & 16 & 2 & 31 & 7 & 51 & 1 & 53 & 161 \\
\hline
\end{tabular}

Fig. 2. Número de yacimientos peninsulares con restos de caballo desde el Epipaleolítico/Mesolítico hasta la Edad del Bronce, según Morales et al. (1998: tabla1).

De los estudios arqueozoológicos se desprende que las muestras son poco representativas a nivel cuantitativo y cualitativo, además de exhibir un grado de fracturación que limita la posibilidad de obtener una amplia base de datos osteométrica. 
A pesar de que en los yacimientos del Holoceno inicial los restos de caballos suelen estar escasamente representados dentro de la fauna silvestre, un mayor consumo del mismo en algunos yacimientos ha querido ser interpretado como un indicio de domesticación (Riquelme, 1995; Uerpmann, 1995), cuestión discutida e incluso pendiente para algunos poblados calcolíticos. Mientras que en Zambujal, Castillejos de Montefrío y Millares los restos de caballo se asignan al agriotipo (Driesch y Boessneck, 1976; Ziegler, 1990; Peters y von den Driesch, 1990), en otros yacimientos más orientales como el Cerro de la Horca y Fuente de Cantos los caballos se consideran en proceso de domesticación (Castaños, 1992).

La principal problemática en reconocer procesos de domesticación radica en que no se aprecian importantes diferencias en la variación de criterios osteométricos entre las muestras del Neolítico hasta la Edad del Bronce (Driesch y Boessneck, 1976), por lo que Uerpmann se reafirma en la domesticación local del caballo en el ámbito peninsular, descartándose también la hipótesis expuesta en su día sobre la rápida expansión del vaso campaniforme a través del caballo como medio de transporte (Schüle, 1969a: 91).

Generalmente, se asume que a partir de la Edad del Bronce los caballos encontrados entre los desechos alimentarios de los poblados son domésticos. Aunque en la mayoría de los yacimientos peninsulares las muestras equinas continúan siendo pobres, despuntan algunos poblados con una representatividad espectacular, caso del Cerro de la Encina (Granada) (Lauk, 1976, Friesch, 1978), el Acequión (Albacete) (Liesau, et al., inédito), o se concentran en determinados recintos como en la fortificación de Peñalosa (Jaén) (Sanz y Morales, 2000) (Figura 3).

A partir del Bronce Final y con la llegada del mundo colonial tenemos que enfrentarnos con unas dificultades añadidas que para nada permiten esclarecer las características propias osteométricas y morfológicas de los caballos prerromanos: la hibridización. Hasta la fecha se sigue confirmando la hipótesis enunciada en su día por von den Driesch (1972) que el mundo fenicio introduce el asno en la Península Ibérica. Mientras que sus restos se documentan en las principales estaciones fenicias durante la Primera Edad del Hierro, el asno se incorpora y se generaliza en el interior peninsular durante la Segunda Edad del Hierro (Liesau, 1998).

La llegada del asno permite realizar una serie de cruces con los caballos obteniendo diferentes híbridos infértiles pero útiles de cara al trabajo de carga y transporte como son las mulas y los burdéganos. Las diferencias osteomorfológicas son difícilmente apreciables, aunque si se observa cierta variabilidad de las tallas y una la constitución más esbelta de los huesos. Con este nuevo panorama, durante la Primera y Segunda Edad del Hierro volvemos a enfrentarnos a un registro óseo muy exiguo en los poblados, siendo bastante excepcionales otro tipo de depósitos.

Sin ánimo de extendernos demasiado en los resultados de los numerosos yacimientos analizados hasta ahora, tan sólo queremos reseñar brevemente los posibles usos de que han sido objeto los caballos en la Península.

Por su elevado rendimiento cárnico el caballo no va ser un recurso alimentario desaprovechado a lo largo de la Prehistoria del que además se utilizaría la piel, el pelo, las crines, los cascos, la grasa, los tendones y los huesos en tareas diversas. Para la industria ósea prehistórica, diferentes porciones esqueléticas serán transformadas y usadas al igual que las de otros taxones, aunque este soporte suele emplearse marginalmente, siendo más frecuente el realizado sobre otras cabañas y taxones silvestres.

Una vez domesticado, la presencia del caballo en la mayoría de los yacimientos suele ser testimonial no superando generalmente el $5 \%$ en representatividad numérica en la muestra faunística. La principal causa de la ausencia del caballo entre los desechos alimentarios puede deberse a que no suele ser una fuente de alimentación relevante y la renovación de la cabaña es más lenta que la de otras especies domésticas (Miguel, 1985). Sin embargo, en relación con el consumo más o menos habitual de la cabaña equina se conocen algunos 
conjuntos faunísticos que destacan por presentar cuantiosos restos, caso de los Tolmos de Caracena (Soto, 1984), El Cerro de la Encina (Lauk, 1976; Friesch, 1987), el Pic de les Moreres (Gil-Mascarell, 1992) o el Acequión (Liesau et al., inédito). Generalmente los restos de caballos corresponden a desechos alimentarios exhibiendo patrones de despiece similares a los del vacuno.

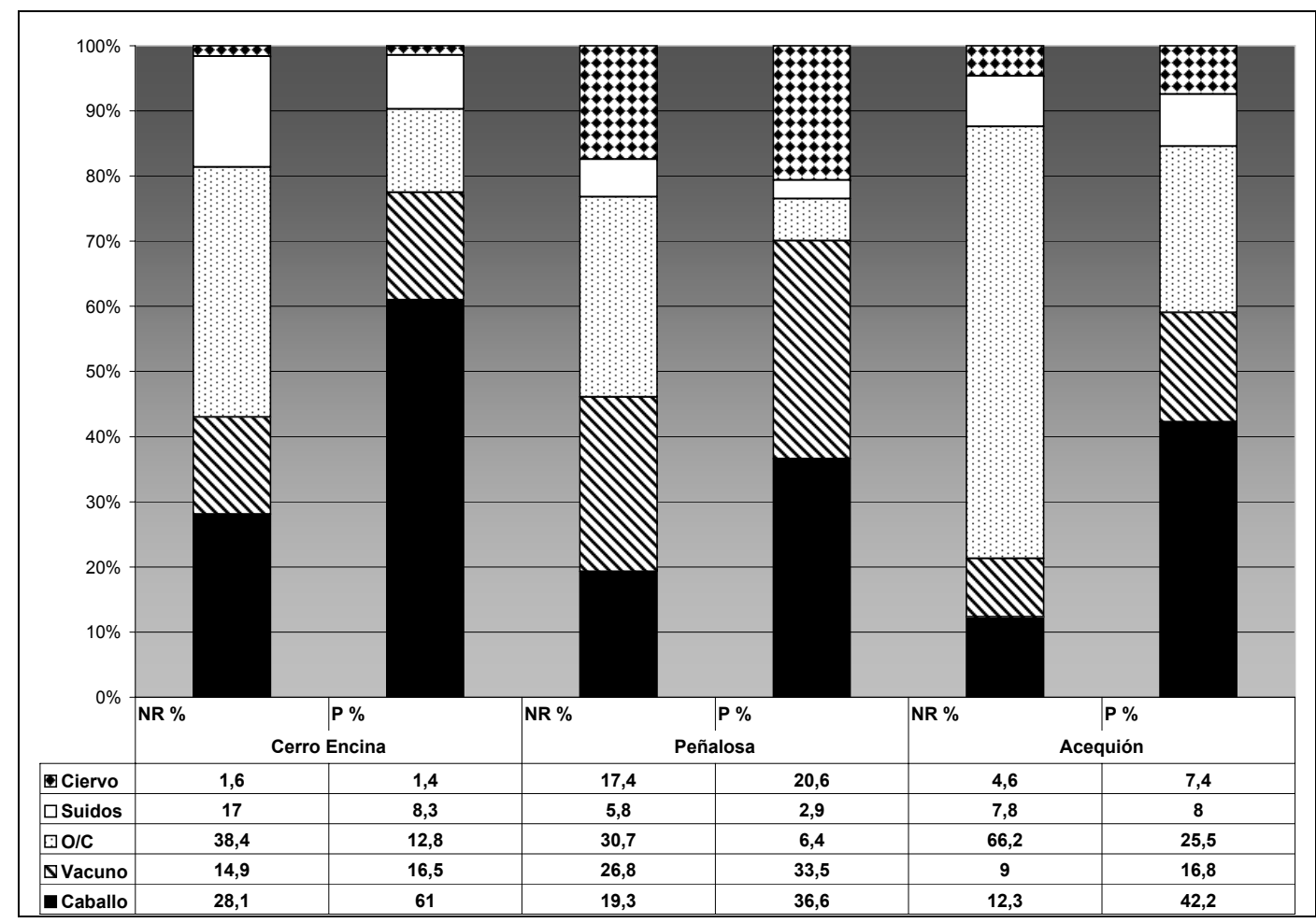

Fig. 3. Relación relativa del número de restos $(\mathrm{NR})$ y peso $(\mathrm{P})$ entre los principales proveedores de carne para tres yacimientos de la Edad del Bronce: Cerro de la Encina (Lauk, 1976) Peñalosa (Sanz y Morales: 2000) y el Acequión Liesau et al. (inédito) (En los suidos y ovicaprinos quedan incluidos agriotipos, como el jabalí y la cabra montés).

En la Figura 3 se reflejan unos histogramas con las proporciones relativas sobre dos parámetros clásicos: el número de restos $(\mathrm{NR})$ y el peso $(\mathrm{P})$, este último que nos indicaría mejor el aporte de la biomasa en función de la talla de cada una de las principales cabañas y fauna silvestre documentada en los poblados. El aporte del caballo en el Cerro de la Encina en relación al peso $(61 \%)$ margina en su totalidad las cabañas restantes, que en el Acequión, aún con un NR de tan sólo el $12 \%$ se constituye también como la principal cabaña consumida (peso: 42,2\%), mientras que en Peñalosa los valores del peso superan también el 36\%, estando equilibrados con el vacuno, dato que difiere bastante con los otros dos poblados. Los restos de caballo en Peñalosa se concentran en el recinto de la fortificación. Esta abundancia de restos respecto a otras áreas del yacimiento ha sido interpretada como un acceso diferenciado a los diferentes rebaños en función de una estructura social jerárquica cuya clase dirigente habitaría en esta estructura (Spanedda et al., 2004). En el Cerro de la Encina, sin embargo, una gran concentración de material en el lado sur del recinto fortificado parece aprovechar una acusada pendiente que permite acumular los desechos alimentarios, especialmente huesos grandes y aparatosos como los de los caballos. Durante el Bronce Tardío se evidencia una concentración habitacional en esta área por lo no se descarta que, una vez agotadas algu- 
nas reservas mineras, el exceso de caballos empleados como animales de carga fue consumido. También cabe la posibilidad que dicha concentración de restos sea el resultado de su consumo como último recurso por causa de unos conflictos bélicos (Friesch, 1987:110, 121).

Aparte de unas condiciones del medio favorables para la cría y manutención de las cabañas equinas en poblados como el Cerro de la Encina o el Acequión el consumo de carne de caballo puede obedecer a unos criterios difícilmente evaluables a partir del registro arqueológico. En estos poblados su carne era muy apreciada, mientras que en otros, incluso próximos, no descartamos un rechazo o tabú, al igual que ocurre hoy en día en diversos ámbitos culturales. Generalmente, el consumo habitual de carne de caballo suele ser menos probable cuando los lazos sociales y afectivos con el animal son muy estrechos, algo que ocurre sobre todo cuando es empleado para la monta.

Los excedentes que se consumen en ambos poblados difieren en el perfil de edades; mientras que en el Cerro de la Encina se sacrifican animales adultos y seniles, no ocurre los mismo en los ejemplares procedentes de El Acequión en el que quedan incluidos infantiles, juveniles y subadultos, documentados además en diferentes unidades de habitación, basureros, zonas de paso a lo largo de todas las fases. ¿Podría tratarse de selecciones intencionadas de las que son eliminados todos aquellos individuos poco dóciles o menos aptos para determinadas tareas? En un biotopo, posiblemente apto para la cría y manutención de grandes yeguadas cabe plantearse otra pregunta inquietante: ¿Corresponden realmente todos los restos recuperados a fauna doméstica o podrían haber sobrevivido reducidas poblaciones de équidos silvestres en aquellos biotopos favorables, conocidos históricamente como lugares con una larga tradición de cría caballar? Una cuestión clave que sigue sin determinar es nuestro desconocimiento de la extinción, no sólo del caballo silvestre (Uerpmann, 1990: 123), sino también del asno silvestre, zebro o encebro. Es precisamente en la provincia de Albacete donde las fuentes históricas nos hablan del zebro como animal muy apreciado y con un elevado valor cinegético que sobrevivió hasta el siglo XVI, mientras que en el centro y sureste peninsular se había extinguido siglos antes (Nores y Liesau, 1992).

Para la Primera Edad del Hierro los datos faunísticos son poco elocuentes a la hora de valorar la importancia del caballo. La gran mayoría de poblados contienen únicamente restos de caballos adultos y seniles, consumidos una vez cumplidas sus funciones como es Sacaojos (Driesch y Boessneck 1980) (Figura 4). El Castro de Baraones, Sacaojos, La Coronilla y, especialmente, yacimientos del Valle del Ebro como La Hoya, Peñas de Oro, Castillo Henayo, Castillo de Mendavia y Berbeia, los restos de caballo no suponen más del $2 \%$ en cuanto al número total de restos identificados y un $8 \%$ en relación al peso. Sólo en Berbeia se alcanza el 12\% (Liesau y Blasco, 1999). Maya (1992) destaca también para otros yacimientos del Bajo Valle del Ebro la escasa importancia que tiene el caballo como recurso alimentario, siendo más bien un elemento de prestigio y de monta individual, también vinculado a ideologías de ultratumba.

Dos yacimientos resultan ser excepcionales en relación con los restos de caballos documentados. En el yacimiento vallisoletano de El Soto de Medinilla el aporte de los caballos, especialmente en relación al peso $(25 \%)$ destaca su relevancia en relación con otras cabañas en las que prima el ganado vacuno, además de una actividad cinegética nada despreciable (18\%) ¿El aumento del consumo de caza puede ser resultado del empleo de novedosas estrategias cinegéticas a caballo? Este es otro yacimiento clave en el que se consumen numerosos machos subadultos y nos planteamos en su día si ese importante excedente se debía a una posible selección de individuos de cara a su cría, ya que no se explica muy bien la razón de sacrificar tantos adultos jóvenes en su edad óptima para el adiestramiento en la monta, carga, tiro o como elemento de intercambio (Liesau, 1994, 1989). Otro yacimiento seleccionado es Santa Ana en el que se han localizado dos pozos votivos que comentaremos a continuación. 


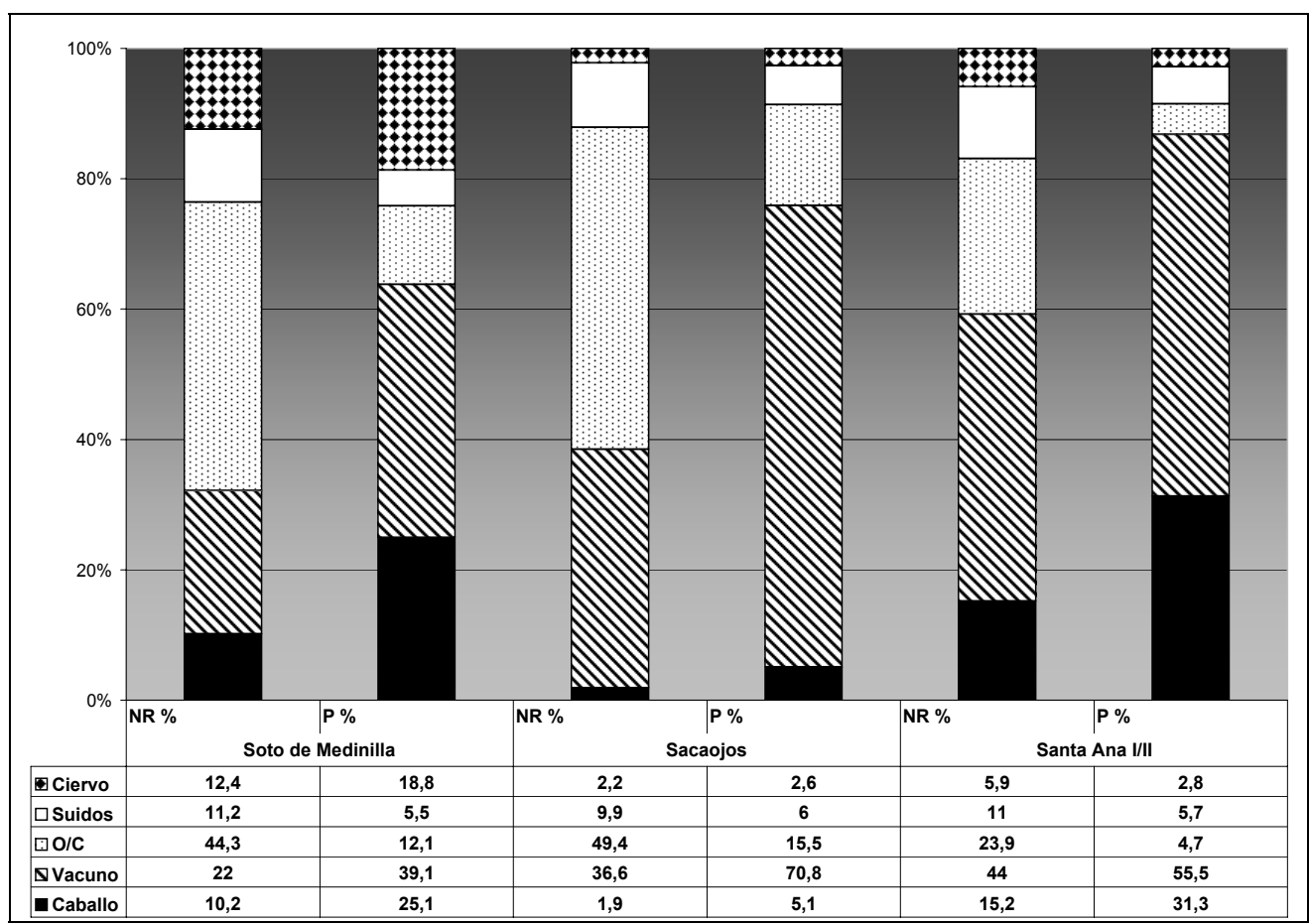

Fig. 4. Relación relativa del número de restos (NR) y peso $(\mathrm{P})$ entre los principales proveedores de carne para tres yacimientos de la Primera Edad del Hierro: El Soto de Medinilla (Liesau, 1998) Sacaojos (Driesch y Boessneck, 1980) y Santa Ana I/II (en el foso II sólo los niveles 4 y 5) (Miguel y Morales, 1985) (En los suidos y ovicaprinos quedan incluidos agriotipos, como el jabalí y la cabra montés).

Durante la Segunda Edad del Hierro, en cambio, sí se observan cambios notables en El Soto de Medinilla. En este caso los restos de caballos aparecen de forma marginal con un 1,1 $\%$ número de restos y un $3,7 \%$ en relación al peso. Por tanto, los resultados obtenidos para este período denotan un comportamiento totalmente distinto al de la etapa anterior, pero más concordante con lo sabido de asociaciones faunísticas peninsulares en general (Liesau, 1994, 1998; Morales y Liesau, 1995).

Los datos obtenidos para conocer la altura media en la cruz de los caballos prehistóricos son bastante exiguos debido al elevado grado de fracturación que suelen exhibir las muestras. Tanto para el Calcolítico como para la Edad el Bronce se describe, fundamentalmente a los caballos andaluces, como de talla media con una altura media en la cruz de entre 130-145 cm. siendo, generalmente, de constitución esbelta y con cascos estrechos (Driesch, 1972:27, Lauk, 1976: 17, Friesch, 1987: 63). Durante la Edad del Hierro en el Soto de Medinilla se han hallado rangos que abarcan desde 137-142 cm., que entran dentro del margen de variación de otros poblados del Hierro como Sacaojos o el Castro de Ubierna, La Hoya o Peñas de Oro (Liesau, 1998; Driesch y Boessneck, 1980; Castaños, 1989; 1980, 1990). Sin embargo, con las debidas precauciones por la ausencia de una base de datos representativa, parece que superan ampliamente la alzada de algunas razas primitivas, como el actual poni vasco o el asturcón, con unas alturas medias en la cruz que no superan los $125 \mathrm{~cm}$. (Altuna, 1980; Álvarez Sevilla, et al., 1995).

El uso del caballo como animal de carga, tiro o monta es un aspecto más complejo que, desgraciadamente, no siempre se evidencia en el registro óseo. Los perfiles de edad, 
como con un predominio de animales adultos y seniles, además de la presencia de animales castrados, documentados a partir de la Edad del Bronce, pueden ser algunas evidencias de patrones de uso, mientras que determinadas anomalías dentarias y paleopatologías suelen reflejar un sobreesfuerzo físico del animal.

Paleopatologías sobre el esqueleto apendicular no se han descrito muchas, tal vez sólo mencionar una falange procedente de Peñalosa que exhibe un «anillo óseo alto» y que hace sospechar a los arqueozoólogos que los caballos fueron empleados para la tracción de grandes pesos (Sanz y Morales, 2000:232).

Más frecuentes suelen ser algunas evidencias debido al uso de diferentes tipos de arreos, aunque también muy discutidas entre los especialistas. Las alteraciones osteológicas observadas por el uso de arreos pueden manifestarse en diferentes porciones anatómicas. Como ya advirtió hace tiempo Azzaroli, el uso incorrecto de las embocaduras en la antigüedad, era más bien la regla que una excepción (Azzaroli, 1985). Arreos mal adaptados pueden, no sólo producir irritación gingival, sino provocar procesos de exóstosis (Littauer, 1969), además de causar erosiones óseas puntuales tal y como se ha documentado en una rama horizontal de una mandíbula de una mula (fig 5.). La presión mecánica reiterada y excesiva de diferentes tipos de arreos con embocaduras, muserolas, quijeras e, incluso, bozales ha permitido iniciar nuevas líneas de investigación de cara al uso de los caballos a lo largo de la Prehistoria (Bökönyi, 1968; Armitage y Chapman, 1979, Anthony et al., 1991).

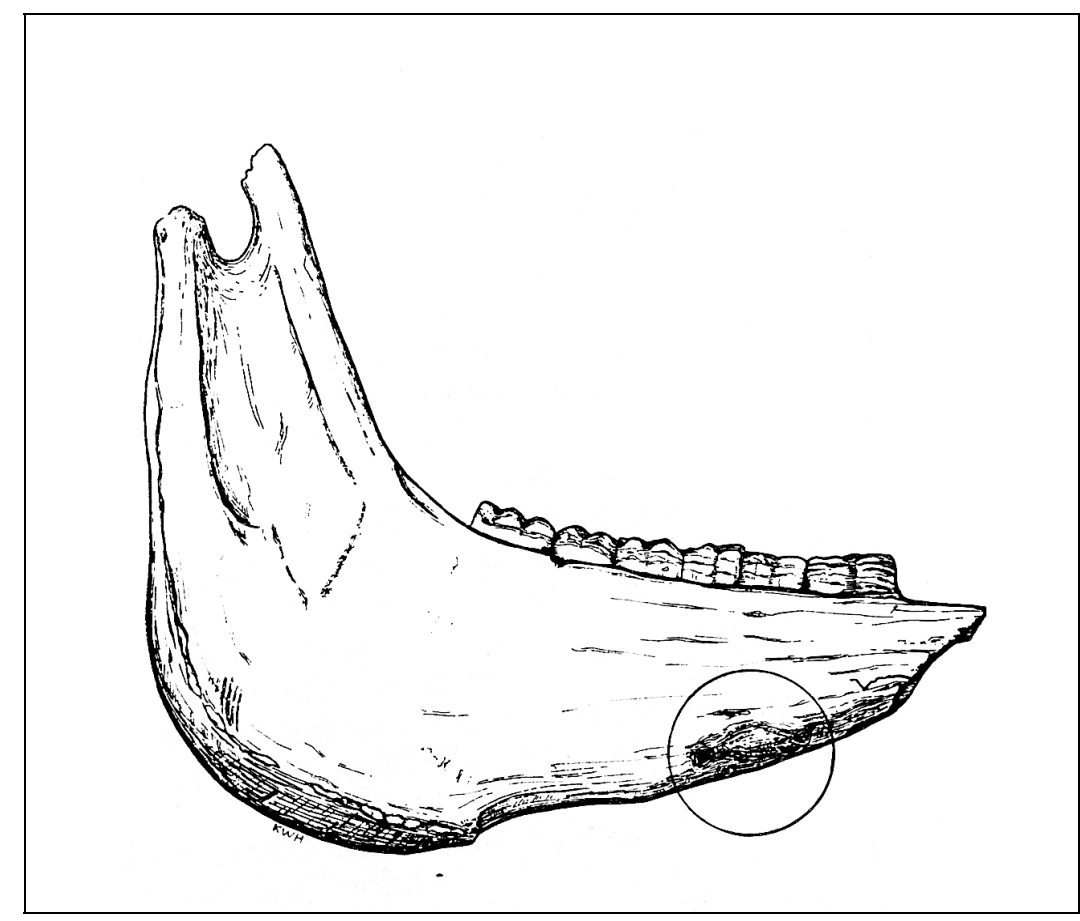

Fig. 5. Detalle de la erosión ósea producida por una excesiva presión de una muserola o bozal sobre la rama horizontal de una mula (Armitage y Chapman, 1979).

La utilización de arreos con embocaduras puede producir algunos desgastes característicos en los segundos premolares equinos. En contextos de hábitat del Hierro I de El Soto de 
Medinilla apareció un fragmento anterior de mandíbula de un garañón, que sólo conserva el segundo premolar izquierdo con un desgaste muy acusado y peculiar que afecta a toda la zona oclusal anterior y en perfil forma una línea curva oblicua que cae oralmente hacia la parte anterior de la parte anterior de la boca. Esta abrasión desigual del diente, así como la observación de estrías paralelas al eje longitudinal del diente y un proceso de inflamación en la cara lingual alrededor del alveolo del premolar que se denomina diastema o asiento parece indicar un roce continuo y repetitivo de un objeto extraño en sentido oral-aboral en la boca del animal (fig. 6). Estas observaciones, descontextualizadas, no permitirían postular la existencia de una embocadura, máxime cuando no se ha podido recuperar el antagonista superior que permite fehacientemente descartar una maloclusión (Levine et al., 2002: 69). Sin embargo, en nuestro caso, la forma de abrasión del diente, el tipo y direccionalidad de las huellas, y el proceso inflamatorio exclusivo en el margen labial refuerzan la hipótesis anteriormente avanzada. Parece, por tanto, tratarse no sólo de un bocado, posiblemente metálico, que sensibiliza las comisuras de los labios del animal, sino que a través de las riendas ejerce además una presión notable sobre todo el área del asiento tal y como queda reflejado en la Figura 7.

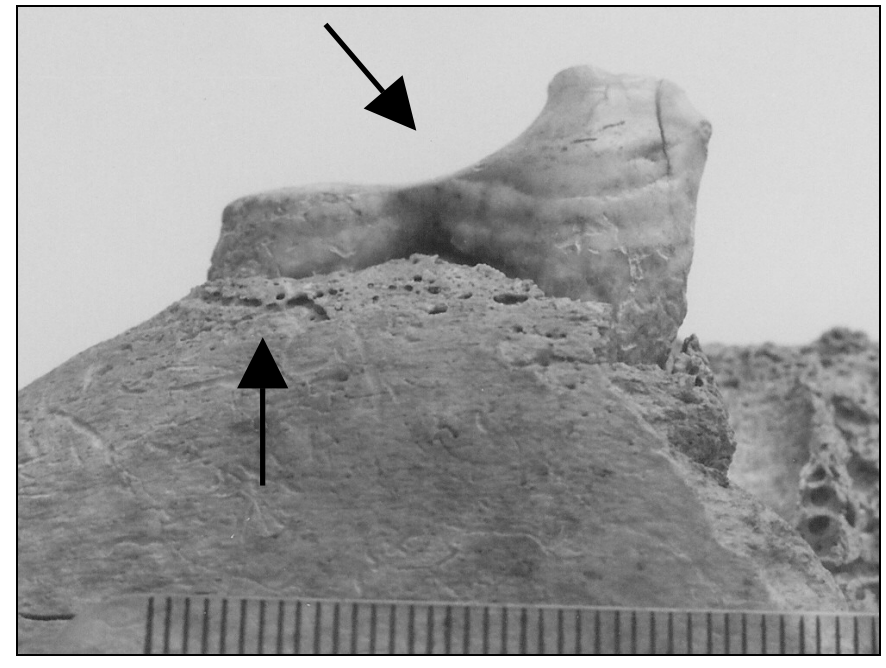

Fig. 6. Detalle del segundo premolar inferior de un garañon hallado bajo el relleno de cimentación de una casa circular de El Soto de Medinilla. Destaca un desgaste muy acusado de la superficie oclusal y una alteración del tejido alveolar en el margen labial, (escala en mm.)

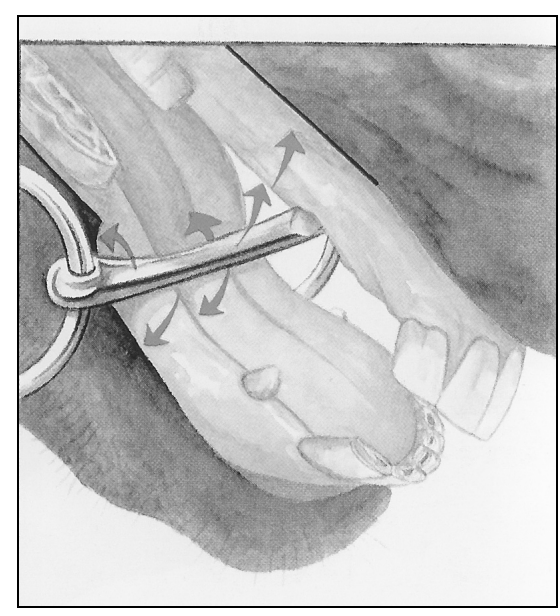

Fig. 7. El bocado rígido actúa sobre la lengua y el diastema en las direcciones indicadas por las flechas, según Webber (2003: 24).

Aunque este tipo de abrasión que acabamos de documentar no es excepcional, son escasas las evidencias publicadas. Proceden fundamentalmente de registros funerarios hallstatticos, escitas, y de Egipto (Bökonyi, 1968; Azaroli, 1985; Levine et al., 2002; Clutton-Brock, 1974). En un futuro, sería oportuno retomar un estudio dentario enfocado a poder observar huellas de desgaste en todos aquellos depósitos de caballos, portadores de la evidencia más directa - el bocado - máxime cuando los estudios de desgastes se han perfeccionado y contrastado experimentalmente (Brown y Anthony, 1998).

Sobre la discutida cuestión de la aparición de la embocadura para la utilización del caballo como animal de tiro, al parecer, no necesario para la monta, es muy probable que los diferentes sistemas de arreo para los carros se hayan ido perfeccionando con el tiempo, pero las 
camas en asta aparecen en algunas culturas desde el inicio mismo de la domesticación, y por lo tanto, antes de la invención de la rueda. Por ello, aunque algunos investigadores las asocian directamente con la aparición del carro, la recuperación de una embocadura no implica necesariamente la existencia de un carro. Sin embargo, si parece constatarse una estrecha relación entre determinados tipos de arreos y carros (Piggot, 1983). Por estas razones, y teniendo en cuenta que el Sur de la Península ha podido ser un foco de domesticación local del caballo, las respuestas para su control y manejo se han podido gestar y desarrollar hacia soluciones diferentes, según el uso del caballo y las eficacias de los arreos, aunque el ámbito mediterráneo y continental haya podido influir en la naturaleza del soporte y la morfología de las piezas.

No debemos, por tanto, descartar el empleo de arreos sin embocadura, con sistemas como anillas, bozales o muserolas (denominadas también hackamore mecánico o jáquima) (Hancar, 1956; Littauer, 1969:292; Dossenbach, 1987) que, tal vez pudieran aparecer reflejados en algunas pinturas rupestres con representaciones de équidos y figuras humanas, en las que en ciertos casos, la cuerda no parte directamente de la boca por debajo, sino por encima (Lucas y Rubio, 1990:442). Tampoco es de extrañar que algunos restos conservados de mecanismos efectivos a la hora de controlar a los équidos no se hayan conocido como tales, como apunta Lichardus (1980:14, quien ha comprobado experimentalmente la eficacia de las camas de tipo Ostdorf; Kurtz (1990:242) hace lo propio para piezas metálicas; mientras que Roes (1960) menciona la existencia de psalia en asta aparecidos en Numancia y Palencia, que Lucas y Rubio (1990:241, notas 20 y 21), con las debidas reservas cronológicas, relacionan con las de los poblados de La Hoya y el Castro de Peñas de Oro y que en la actualidad también se documentan en los niveles del Hierro I de Soto de Medinilla- curiosamente en la misma unidad de la que procede la mandíbula de caballo antes descrita - así como piezas más antiguas, es decir del Bronce Tardío procedentes de Fuente Álamo y otras similares encontradas por E. y L. Siret en el mismo yacimiento (Arteaga y Schubart, 1980:273) (Figura 8).

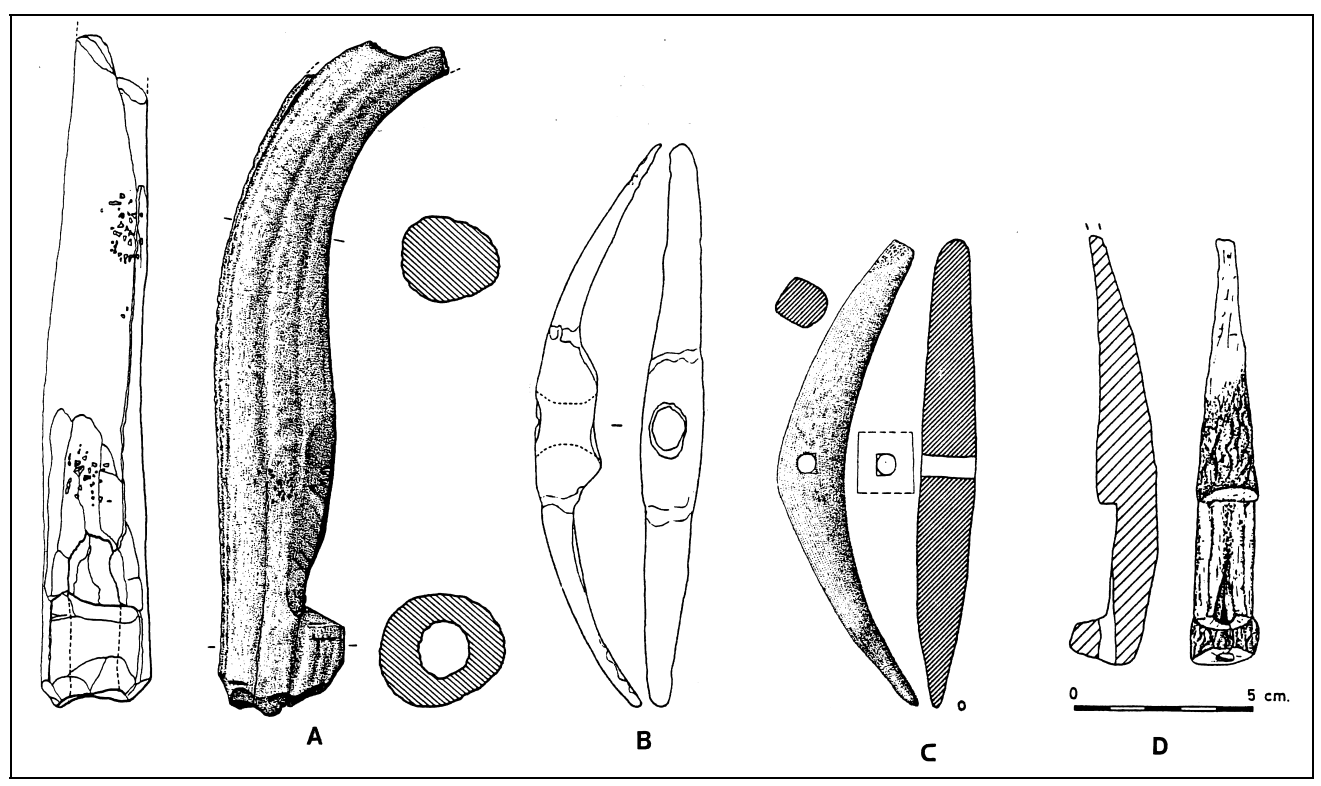

Fig. 8. Camas de bocado de: A- El Soto de Medinilla, Hierro I (Liesau, 1998;E.1:2); Btipo Ostdorf (Lichardus, 1980: fig. 1B2; E. 1:2); C- Fuente Alamo (Schubart y Arteaga, 1980, Fig. 12-0; E. 1:2); C- El Soto de Medinilla Hierro II (Escudero y Balado, 1990: Fig. 2,1). 


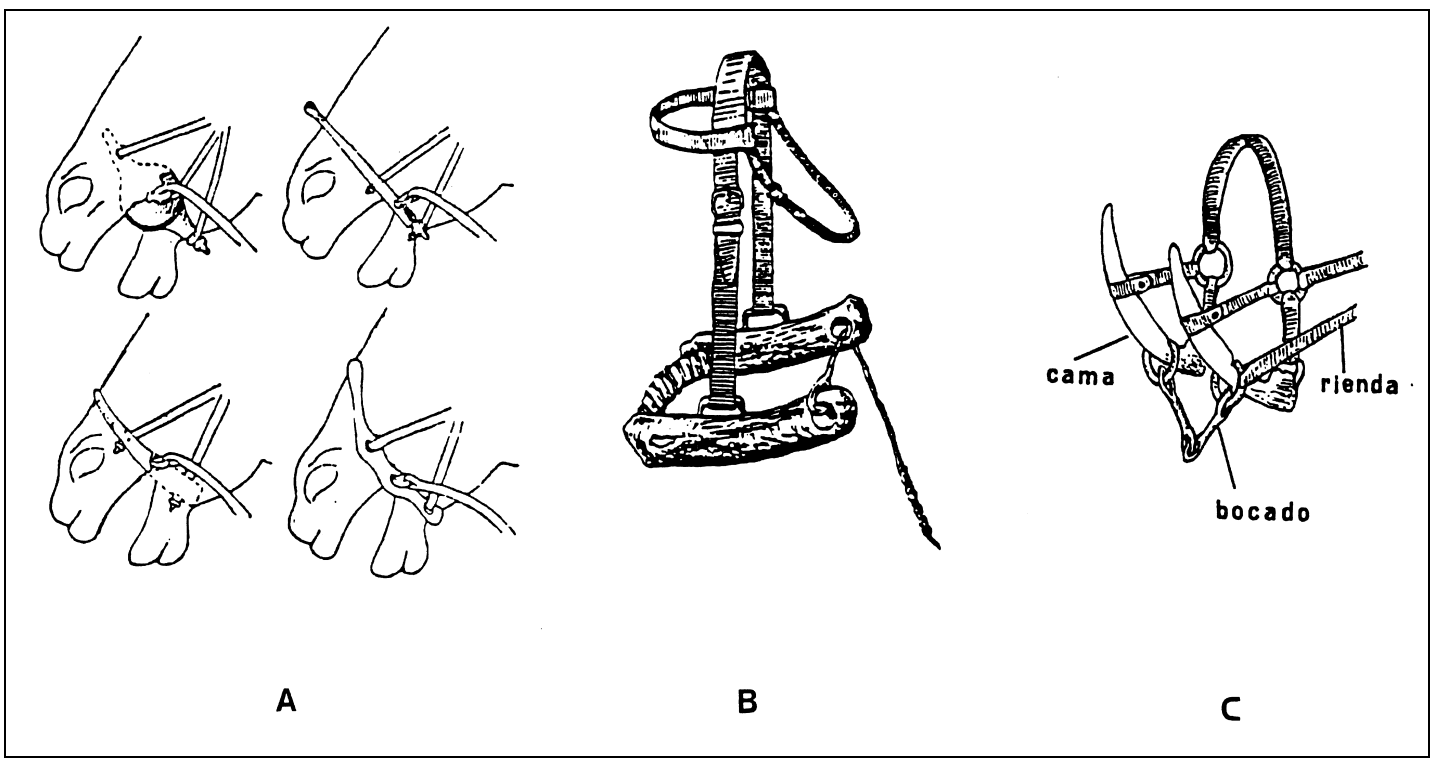

Fig. 9. Reconstrucciones de diferentes arreos con camas y embocaduras: A- según Smirnov, en Azzaroli (1985: fig. 8); B- según Gautier (1990:173); C- según Escudero y Balado (1990: fig. 6:2).

También Escudero y Balado (1990) han interpretado como psalia, varias camas en asta procedentes de diferentes poblados de la Segunda Edad del Hierro, aunque de tipología diferente, pero con antecedentes europeos y asiáticos de la Edad del Bronce. En su estudio citan a Llanos, Paulsen y Schulten quienes asignan a estas piezas una funcionalidad de silbos o silbatos, y que no consideran suficientemente fundamentada. Las piezas documentadas hasta ahora sólo en poblados de la Meseta Septentrional y del Valle del Ebro, son contemporáneos con los arreos metálicos de las necrópolis, proponiendo los autores varias formas de utilización de los psalias celtibéricos en combinación con piezas de metal o materiales orgánicos (Figura 9).

En el uso del caballo como animal relacionado con el mundo simbólico tendríamos que incluir en este apartado los ídolos realizados sobre centenares de falanges, ampliamente documentadas en numerosos megalitos del Sur y Sureste peninsular. La mayoría están decoradas con diferentes técnicas y motivos en un soporte en el que priman las primeras falanges de artiodáctilos como las de cérvidos y bóvidos, $\mathrm{y}$, en menor medida équidos formando parte del ritual funerario (Siret, 1890; Leisner, 1943). Se percibe una tendencia a emplear la articulación proximal como superficie de base que permite poner de pie el hueso, mientras que la articulación distal se rebaja y se estiliza a modo de cabeza alada siendo frecuentes decoraciones de carácter antropomorfo (Leisner, 1943; Meier 1962) (Fig. 10 A y C).

En este sentido nos planteamos algunos interrogantes acerca del empleo de las falanges equinas para su transformación y/o decoración en ídolos: ¿los grupos megalíticos que incluían estas piezas en sus contextos funerarios eran realmente concientes del empleo de falanges de caballos ó se trata sencillamente de una morfología más adecuada que la de otros ungulados para plasmar en ellas características antropomorfas, sobre todo femeninas? (Fig. 10 B).Otro dato que apuntaríamos de cara a una falta de intencionalidad y uso deliberado de los ídolos-falange por el significado que pudiera tener el hecho de utilizar un hueso de naturaleza equina son las imitaciones de falanges en otros soportes como en piedra o terracota (Leisner, 1943). 


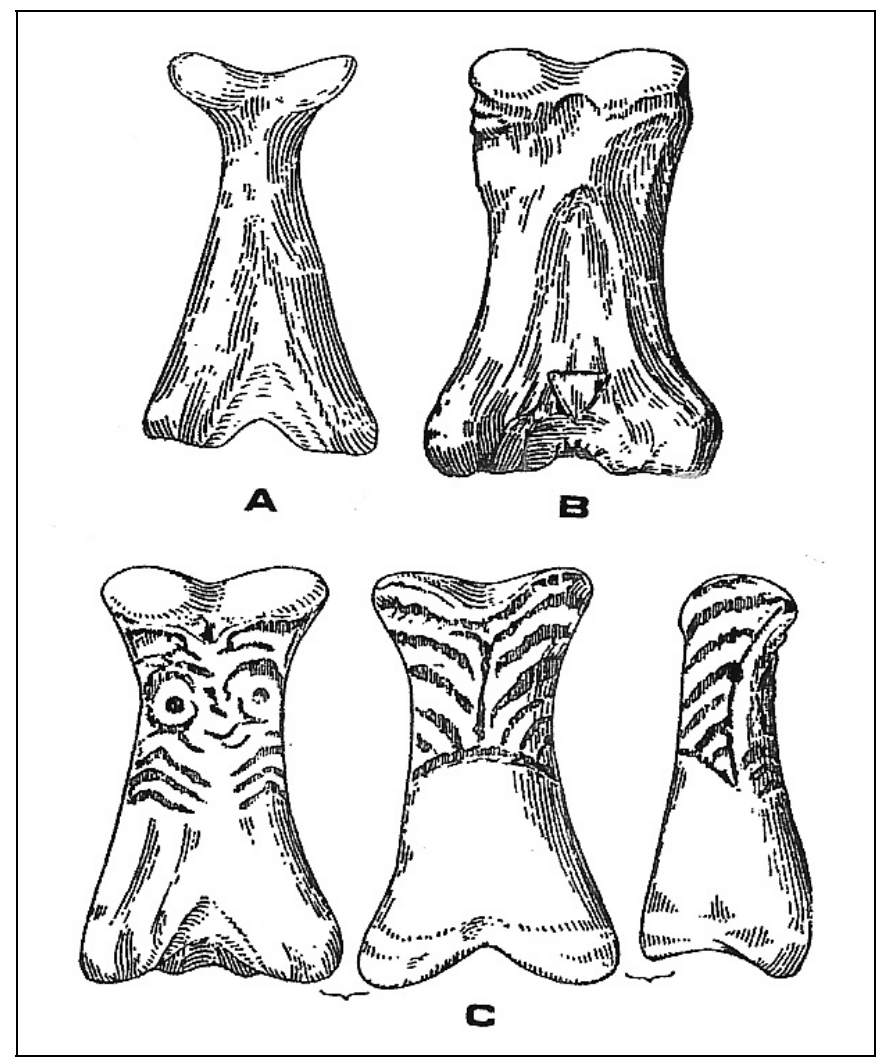

Fig. 10. Idolos-falanges de caballo modificadas procedentes de A: Los Millares 45,4 (Granada); B: Cabecito de Aguilar 2 (Mojácar); C: Los Castellones 19 (Granada) ( según Leisner 1943, láminas 17, 29 y 40 respectivamente). $\mathrm{E}=1: 2$.

En relación a las implicaciones rituales de los depósitos de la Edad del Hierro de Santa Ana (Logroño) el contexto en el que han sido hallados estos restos, parece estar bien definido. Se trata de dos grandes hoyos con una potencia superior a $3 \mathrm{~m}$. estaban rellenos con abundante material arqueológico y restos de fauna. Ambos hoyos han sido considerados como depósitos votivos, y se incluye al caballo, junto con otras especies domésticas, como una de las principales especies sacrificadas (González Blanco et al., 1985). Con un 9, \% en NR de restos identificados y $25 \%$ en el peso, son muy similares a los obtenidos en El Soto de Medinilla sacrificándose numerosos individuos, casi todos subadultos incluidos tres castrados (Miguel y Morales, 1983; 1985).

Otro hallazgo sorprendente procede del yacimiento ibérico de Els Vilars, donde se hallaron hasta seis deposiciones de fetos de équidos en un contexto habitacional. La interpretación de este registro ha sido relacionada con la emergencia de una aristocracia militar ecuestre (Gómez, 2003) o el depósito ritual de San José de Alcalá Xivert (Iborra, 2003), aspecto interesante cuando en el mundo ibérico el caballo, lejos de ser objeto de ofrenda para el más allá, es él mismo sepultado junto con su arreo como en la Regenta en Burriana (Mesado, 2003).

En este apartado tenemos que mencionar también el Castrejón de Capote (Badajoz), un santuario, en el que junto al altar se recuperaron ofrendas cerámicas y abundante fauna (Berrocal-Rangel, 1994) Se trata fundamentalmente de fauna doméstica en la que quedan incluidos 
varios restos de équidos, uno de ellos en conexión anatómica, es decir un miembro posterior casi completo de un asno y algunos otros de mula o asno calcinados, todos ellos representan un de escaso valor cárnico (Morales y Liesau, 1994). Aún mayor interés desde el punto de vista arqueozoológico será conocer en su día los resultados del estudio de numerosos équidos recuperados en el interior del palacio santuario de Cancho Roano en el que además se recuperó una figura de équido en bronce (Celestino y Julian, 1991; Celestino et al. 1996).

No cabe duda que el caballo a lo largo de la Pre y Protohistoria adquiere cada vez más importancia. De mero recurso alimentario pasa a desempeñar el papel de animal de carga y transporte y llega a convertirse en un elemento de prestigio y riqueza, animal de culto de carácter astral y psicopompo aunque en todo lo relacionado con los sacrificos, Bermejo (Sánchez Moreno, 1995: 96) se muestra cauteloso por la falta de documentación arqueológica. (Schulten, 1920; Blázquez, 1954, 1957; 1977; Sopeña, 1987; Bermejo, 1986: 95)

A pesar de que nosotros no queremos abordar este aspecto más que de forma tangencial que ya ha sido tratado extensamente, incluso de forma monográfica en libros como los de $\mathrm{Al}$ Andalus y el caballo (1995) o el de El caballo en la Antigua Iberia (Quesada y Zamora, 2003) si nos gustaría insistir sobre algunas citas de las fuentes clásicas cuando alaban las excelencias de los caballos hispanos. Sobre la domesticación y manejo caballar, las Fuentes Clásicas se nos antojan excesivamente literarias cuando dejan entrever la gran facilidad con que los pueblos prerromanos capturaban a los caballos salvajes, según sus necesidades bélicas o cotidianas. Aunque reiteradamente se destacan las grandes capacidades de doma y adiestramiento de estos pueblos, no tienen, en realidad, demasiado en cuenta el significado de las especies silvestres y a los cimarrones. El proceso de la doma y el adiestramiento de los caballos es bastante más complejo - requiere mucha paciencia, tiempo y atención constante - siendo inviable realizar simples batidas para en breve tiempo domar y conseguir la docilidad necesaria de cara a determinados usos domésticos o militares. Seguramente, y como ya han apuntado diversos autores, las informaciones recogidas o transmitidas, adolecen de una visión sesgada en parte de culturas civilizadas frente al salvajismo cuya conquista queda justifica, aunque en otras ocasiones, como parece ser este caso, se ensalzan las cualidades del buen salvaje (Ruiz-Gálvez, 1991; Álvarez Sanchis 1991). Por tanto, parece más factible pensar que estos pueblos disponían de numerosas yeguadas en estado de semilibertad. De esta forma, bajo cierto control se resolverían, a la vez, las exigencias alimentarias de estos animales. Algo similar se observa aún hoy en día en las yeguadas gallegas, asturianas y vascas en las zonas de montañas.

Pasando a entrar a considerar al caballo en un aspecto relacionado con el ámbito funerario, las evidencias hasta ahora documentadas son bastante exiguas. En este tipo de contexto siempre conviene evaluar adecuadamente si los restos de fauna realmente constituyen un depósito intencionado, descartando intrusiones de restos óseos fragmentados y en desconexión anatómica. Restos de caballo asociados al mundo funerario suelen ser poco frecuentes. En este sentido cabe destacar una presencia mayoritaria de otras especies domésticas, como los ovicaprinos, el vacuno y el porcino, además de algún taxón silvestre. De Fuente Álamo, donde se ha podido estudiar un patrón de deposición animal en cierta medida estandarizado, se ha documentado el caballo tan sólo de la tumba doble 69 correspondiente al Bronce Antiguo (El Argar A 1; Schubart, 2001). El tipo de cista, el ajuar, su cerramiento con una estela antropomorfa (Schubart y Risch, 1990) el depósito asociado de parte de una pata de vacuno revela un tipo de enterramiento de elevado rango social (Liesau y Schubart, 2004). Excepcional resulta también el hallazgo de una escultura con una cabeza de équido y de ave de Los Cipreses como elemento de señalización de la boca de un pithos argárico (Ayala et al., 2000).

Evidencias directas de caballos completos enterrados en las necrópolis son tardías y parece tratarse más bien de casos aislados como el de de Saula (Schüle, 1969b) o La Pedrera 
donde Maluquer (1968), menciona una sepultura con dos caballos enterrados, de los que uno llevaba una cabezuela de bronce. Este autor no descarta que fuera una tumba con caballos y carro, cuestión que no se ha podido concretar, debido a que no se excavó en su totalidad, aunque posteriormente se citan depósitos de caballos en tres casos para esta necrópolis (Maya, 1992). En la necrópolis de Sansol junto a una serie de tumbas de inhumación se pudieron identificar restos de, al menos, tres caballos, uno de ellos próximo a una de las tumbas portando además una embocadura (Castiella, 1988; 1990, Castaños, 1988). Pero cuanto más avanzamos en la Edad del Hierro los restos de caballos son cada vez más escasos, no sólo en los poblados, sino resulta cada vez más complejo poder reconocer algunos patrones de deposición características como ocurre en las necrópolis de Ucero y la de Las Ruedas en la que se recuperaron piezas dentarias en numerosas tumbas, además de algunos fragmentos de huesos apendiculares (García-Soto, 1990; Sanz Mínguez, 1990; Bellver, 1995). En esta última necrópolis los restos de caballos están siempre asociados a otras especies aunque, a excepción de las piezas dentarias, no parece que se pueda reconocer una tendencia deposicional mejor caracterizada para las gallinas, liebres, porcino y ovicaprinos. Algo similar podemos observar también en el ámbito íberico y fenicio-púnico, los restos de caballos suelen estar ausentes o son escasos, siendo otras especies las protagonistas como ofrendas animales (Miró, 1992; Castaños, 1994; Torres, 1999).

A medida que avanzamos hacia las etapas prerromanas la repercusión de la imagen del caballo y el trasfondo cultural reflejado en numerosas de piezas realizadas en todo tipo de soportes adquiere un rango excepcional, pero resulta imprescindible localizar nuevos hallazgos para contrarrestar el paupérrimo registro arqueozoológico documentado hasta la fecha y poder avanzar en nuestros conocimientos a través de las evidencias arqueológicas directas, el registro óseo... Esperemos que en un futuro próximo la Arqueozoología en estrecha colaboración con otras líneas de investigación interdisciplinares, pueda esclarecer numerosas incertidumbres sobre los orígenes del caballo doméstico y el complejo panorama que exhibe el surgimiento de las razas arcaicas en el ámbito peninsular.

Corina Liesau Von LetTow-Vorbeck

Dpto de Prehistoria y Arqueología - Universidad Autónoma de Madrid

\section{BIBLIOGRAFÍA}

Altuna, J. (1972): Fauna de mamiferos de los yacimientos prehistóricos de Guipúzcoa. Munibe, 24.

(1980): Historia de la domesticación en el País Vasco desde sus orígenes hasta la Romanización. Munibe 32.

(2002):»Los animales representados en el arte rupestre de la Península Ibérica. Frecuencias de los mismos.» Munibe 54, 21-33.

Guipúzcoa)». Munibe, 30 .

y APELLANIZ, J.M ${ }^{\mathrm{a}}$ (1978): «Las figuras rupestres paleolíticas de la cueva de Ekain (Deva

y MARIEZKURRENA, K. (1990): Nourishment of animal origin of the inhabitants of the North of the Iberian Peninsula during the First Millenium before Christ. In: Schibler et al. (Eds.): 1-11

Álvarez Sanchis, J. (1991): «La producción doméstica». En: Los Celtas de la Península Ibérica. (Revista de Arqueología): 76-81.

Álvarez llana, A.; Álvarez Sevilla J; y Jauregui Campos, J. (1995): Asturcones. Caja de Asturias. Oviedo. 
ANTHONY, D. y Brown D. (2003): «The origins of horseback riding». Antiquity, vol 65, nº 246: 22-38. December: 44-48A.

TELEGIN, D. Y Brown, D. (1991): «The origin of horseback riding». Scientific American,

Armitage, P y Chapman, H. (1979): «Roman Mules». The London Archaeologist, vol3, no 13: 339-346.

Arteaga, O. y SchubarT. H. (1980): «Fuente Álamo. Excavaciones de 1977». NAH, 9: 247-289.

Ayala, Ma M., Jiménez, S. Martínez J. PÉRez. Ma C. y Tudela L. (2000): El arte de la cultura argárica. Nuevas aportaciones a la Edad del Bronce Peninsular. III Congreso de Arqueología Peninsular, vol 4. ADECAP, Porto: 587-600.

AZZAROLI (1985): An early history of horsemanship. Brill y Dr. W.Backhuys (Eds). Leiden. 183-192.

BAHN, P. (1978):The «unacceptable face» of West European Upper Paleolithic». Antiquity, 52:

(1980): Crib-biting: tethered horses in the Paleolithic?. World Archaeology, 12(2): 212-217.

(1984): Pre- neolíthic control of animals in Western Europe: the faunal evidence. En Grigson C. y Clutton-Brock, J. (Eds):27-34

Bellver GarRido, J.A. (1995): La necrópolis vaccea de «Las Ruedas», Padilla de Duero (Valladolid): una aproximación arqueozoológica. En: Delibes et al.(eds): 515-527.

BENECKE, N. (1994): Der Mensch und seine Haustiere. Theiss, Stuttgart.

(1999): «Domestikation des Pferdes in Europa und Südwestasien». En Schäffer (Ed.): Domestication of animals interactions between veterany and medical sciences free communications. 30 th Congress of the WAHVM and DVG. Munich.

BERMEJO, J.C. (1986): Mitología y mitos de la Hispania prerromana. Akal, Madrid.

BERROCAL-RANGEL, L. (Ed.) 1994: El altar prerromano de Capote. Ensayo etno-arqueológico de un ritual en el suroeste peninsular. UAM. Madrid.

BLÁZQUEZ, J.Ma(1954): «Dioses y caballos en el mundo ibérico». Zephyrus, V: 193-212.

(1957): «La economía ganadera de la España Antigua a la luz de las fuentes literarias griegas y romanas». Emerita, XXV:159-184.

(1977): Imagen y mito. Estudios sobre religiones mediterráneas e ibéricas. Madrid.

BOESSNECK, J. (1973): «Was weiss man von den alluvial vorgeschichtlichen Equiden der Iberischen Halbinsel?. En Matolsci (Ed.): Domestikationsforschung und Geschichte der Haustiere. Academia Kiadó. Budapest.

BÖKÖNY (1968): Data on Iron Age horses of Central and Eastern Europe. Mecklenburg Collection, I. American School of Prehistoric Research, 25. Peabody Museum, Harvard University: 3-71.

(1987): Problemas arqueozoológicos. En. Lichardus, J.; Lichardus-Itten, M. (Eds.) : La Protohistoria de Europa. Labor, Barcelona.

y MEID (Eds) (1993): Pferdedomestikation, Haustierhaltung und Ernährung. Archäozoologische Beiträge zu historisch-ethnologischen Problemen. Archaeolingua, Serie Minor, 3. Budapest.

BRown, D. y ANTHONY, D. (1998): Bit wear, horseback riding an the Botai Site in Kazakstan. Journal of Archaeological Science, 25: 331-347.

Castaños, P. M. (1986): Los macromamiferos del Pleistoceno y Holoceno de Vizcaya. Faunas asociadas a yacimientos arqueológicos. Leioa. Tesis doctoral.

(1988): «Estudio de los restos óseos de Muru-Astrain». TAN ,7: 221-235.

(1989): «Estudio de los restos óseos del Castro de Ubierna (Burgos)». Kobie ,18: 87-97.

(1992): «Estudio arqueozoológico de la fauna del Cerro de la Horca (Plasenzuela, Cáceres)». Archaeofauna, 1: 127-146.

(1994): «Estudio de la fauna de la necrópolis de Villaricos (Almería). Archaeofauna, 3: 1-12. 
Castiella Rodríguez, A. 1988: «Asentamiento de Sansol (Muru Astrain, Navarra). Memoria de Excavación 1986-88». TAN, 7: 145-220.

(1990): «Enterramientos en el contexto protohistórico de Sansol (Muro Astrain, Navarra). En: Burillo, F. (Coord.): Necrópolis celtibéricas. II Simposio sobre los celtíberos. Institución Fernando el Católico, Zaragoza: 149-157.

Celestino, S. y Julian, J.M.(1991): «El caballo de bronce de Cancho Roano». CuPAUAM, 18: $179-188$.

Jiménez, J.; Martín, A. Hernández, A y PAvón, I. (1996): El Palacio-Santuario de Cancho Roano V-VI-VII. Museo Arqueológico provincial de Badajoz, Madrid.

Clutton-BrocK, J. (1974): «The Buhen horse». Journal of Archaeological Science, 4 (3): 171-175. bridge. (1987): A Natural History of Domesticated Mammals. Cambridge University Press. Cam-

(1995): Origins of the dog: domestication and early history. En: Serpell, J. (Ed.): The domestic dog: its evolution, behavior, and interactions with people. Cambridge University Press. Cambridge: $7-20$.

CROCKFORD, S. J. (Ed.) (2000): Dogs through time: an archaeological perspective. Proceedings of the 1. ICAZ Symposium on the History of the domestic dog. Eigth Congress of the International Council for Archaeozoology (ICAZ 98), August 23-29, 1998. Victoria, B. C. Canada. BAR International Series 889. Oxford.

(2000): «Dog evolution: a role for thyroid hormone physiology in domestication changes». En: Crockford, S. J. (Ed): 11-20.

Delibes, G.; Romero Carnicero, F. y Morales, A. (Eds.) (1995): Arqueología y Medio Ambiente. El Primer Milenio a.C. en el Duero Medio. Junta de Castilla y León. Consejería de Cultura y Turismo. Valladolid.

DRIESCH, A. VON DEN (1972): Osteoarchaologische Untersuchungen auf der Iberischen Halbinsel. Studien über frühe Tierknochenfunde von der Iberischen Halbinsel 3. München.

1973: Nahrungsreste tierischer Herkunft aus einer tartessischen und einer spätbronzezeitlichen bis iberischen Siedlung in Südspanien. Studien über frühe Tierknochenfunde von der Iberischen Halbinsel 4: 9-31.

(2000): «Revision zum Vorkommen des Equus (Asinus) hydruntinus (Regalia 1907) im Chalkolithikum der Iberischen Halbinsel». Archaeofauna, 9: 35-38.

y Boessneck, J. 1976: Die Fauna vom Castro Do Zambujal. Studien über frühe Tierknochenfunde von der Iberischen Halbinsel ,5: 1-129.

y BoESSNECK, J. 1980: Tierknochenfunde aus Sacaojos bei la Bañeza (Provinz León). Studien über frühe Tierknochenfunde von der Iberischen Halbinsel , 7: 122-159.

CONTRERAs (Coord.) (2000): Análisis histórico de las comunidades de la Edad del Bronce del piedemonte meridional de la Sierra Morena y Depresión Linares-Bailen. Proyecto Peñalosa. Arqueología, Monografías 10. Junta de Andalucía, Sevilla.

DossenBACH, H. (1987): El caballo rey. Blume, Barcelona.

EISENMANN, V.(1998): «Quaternary horses: posible candidates to domestication». International Union of Prehistoric and Protohistoric Sciences. Workshops- 6. Tome 1 ABACO, Forlì:27-36.

Escudero NAVARro, Z. y BALAdo, A. (1990): «Sobre los llamados silbatos certibéricos, una propuesta de interpretación». TP 47: 235-250.

FRIESCH, K. (1987): Die Tierknochenfunde von Cerro de la Encina bei Monachil, Provinz Grana$d a$. Studien über frühe Tierknochenfunde von der Iberischen Halbinsel, 11.

Garcia Huerta, Ma R. y Morales Hervás, J. (2004): La Península Ibérica en el II Milenio a.C.: Poblados y Fortificaciones. Ediciones de la Universidad Castilla-La Mancha, Cuenca. 
García Soto, E. (1990): «Las necrópolis de la Edad del Hierro en el Alto Valle del Duero». En: Burillo, F. (Coord.): Necrópolis celtibéricas. II Simposio sobre los celtíberos. Institución Fernando el Católico, Zaragoza: 13-38.

GAUTIER. A. (1990): La domestication. Et l'homme créa ses animaux. Errance, Paris.

GAUTIER, A. (1998): «The unacceptable face» of the Western European Paleolithic revisited: The evidence for the presumed domestication of the horse during that period. International Union of Prehistoric and Protohistoric Sciences. Workshops- 6. ABACO, Foreì. Tome 1: 45-50.

GIL-MASCARELL, M. (1992): «La agricultura y la ganadería como vectores económicos del desarrollo del Bronce Valenciano». Saguntum, 25:49-67.

GómEz FliX, X. (2003): Fetos de équidos en els Vilars (Arbreca, Lleida) En : Quesada Sanz F. y Zamora Merchan, M. (Eds.): 209-217.

González Blanco, A.; Morales, A. y Miguel, J. De 1985: Los fosos del yacimiento de Santa Ana (Entrena, La Rioja), ¿Un quemadero de ofrendas?. CAN XVII Logroño: 47-53

Grigson C. y ClutTon-Brock, J. (Eds) (1984): Animals and Archaeology. Husbandry in Europe. BAR, IS, 227. Oxford

HANČAR, F. (1956): «Das Pferd in Prähistorischer und Frühhistorischer Zeit. Zeitschrift des Instituts für Völkerkunde der Universität Wien.

IBORRA, P. (2003): Équidos y restos faunísticos de la calle San José de Alcalá de Xivert (Castellón). En: Quesada Sanz F. y Zamora Merchan, M. (Eds.): 201-208.

Jansen, T.; Foster, P.; Levine, M.; Oelke, H.; Hurles, M.; Renfrew, C.; Weber, J. Y Olek K. (2002): Mitocondrial DNA and the origins of the domestic horse. PNAS Early edition. www.pnas.org/ cgi/doi/10.1073/pnas.152330099.

JiMENO, A. 1984: Los Tolmos de Caracena (Soria). EAE, 134.

KURTZ, W. (1990): «Los arreos de caballo en la necrópolis de Las Cogotas (Cardeñosa, Ávila). Zephyrus, XXXIX-XL:459-472.

LaUK, H.1976. Tierknochenfunde aus bronzezeitlichen Siedlungen bei Monachil und Purullena (Provinz Granada). Studien über frühe Tierknochenfunde von der Iberischen Halbinsel ,6. München.

LeISNER, G. (1943): Die Megalithgräber der Iberischen Halbinsel. Band I. Der Süden. Römisch Germanische Forschungen, 17. Berlín.

LEVINE, M. (1990): «Dereivka and the problem of horse domestication». Antiquity, 64:727-740.

LEVINE, M.(2004): «Exploring the Criteria of Early Horse Domestication». En Jones, M (Ed.): Traces of Ancestry: Studies in Honour of Colin Renfrew. Mc Donald Institute Monographs. Cambridge: $115-126$.

LEVINE, M.; Whitwell, K.; JefFCOTT, L. (2002): «Romano-British horse burial from Ocklinghám, Suffolk» Archaeofauna 11; 63-102.

Levine, M.; Renfrew, C. Y Boyle, K (Eds.) (2003): Prehistoric Steppe Adaption and the Horse. Mc Donald Institute Monographs. Cambridge.

Liesau Von LetTow-VorbecK, C. (1992): «Ein Beitrag zur Dokumentierung der Pferde als Reit-oder Zugtiere während der frühen Eisenzeit in der Nordmeseta der Iberischen Halbinsel. Der Pferdeunterkiefer von «El Soto de Medinilla». Archaeofauna, 1: 109-120.

1994: Contribución al estudio arqueofaunístico durante la Edad del Hierro en la Submeseta Norte del la Península Ibérica, Publicaciones de la U.A.M. Madrid.

1998: El Soto de Medinilla: Faunas de mamiferos de la Edad del Hierro en el Valle del Duero (Valladolid, España). Archaeofauna, 7.

y BLASCo BosQued, M. C. (1999): «Ganadería y aprovechamiento animal». IV Congreso sobre Celtíberos.-Economía-, Daroca, 1997 .Institución Fernando el Católico. Zaragoza: 119-147.

Pino, B. Albertini, D. y Morales, A. (inédito): Segundo informe del poblado de la Edad del Bronce de «El Acequión» (Albacete). Informe del LAZ inédito nº 1995/20. 
y SCHUBART, H (2004): «Grabanlagen und Beigaben aus organischem Material im Bestattungsritus von Fuente Álamo» Madrider Mitteilungen, 45: 97-107.

LitTAuer (1969): «Bits and Pieces». Antiquity, XLIII, nº 172:289-301.

LUCAS, R. y RUBIO, I. (1990): «Introducción del caballo como animal de montura en la Meseta: Problemática». Zephyrus, XXXIX-XL:437-444.

MaluQuer De Motes, J. (1968): «Panorama económico de la Primera Eddad el Hierro». Primera reunión de Historia. Estudios de la Economía Antigua de la Península Ibérica. Ed. Vicens-Vives: 61-79.

MAYA, J.L.(1992): «Aprovechamiento del medio y paleoeconomía durante las etapas metalúrgicas del Nordeste peninsular». En: Moure, R.A. (Ed.):275-313.

MEIER, R. A. (1962): Neolithische Tierknochen-Idole und Tierknochen-Anhänger Europas. Bericht der.

Mesado Oliver, N. (2003): «El caballo ibérico de la Regenta». En : Quesada Sanz, F. Zamora Merchán, M.(Eds.): 179-186.

Miguel, DE J. (1987): Estudio comparado de la fauna de vertebrados asociados a yacimientos holocénicos ibéricos: Implicaciones paleoeconómicas cronológico-culturales, tafonómicas y metodológicas de los informes faunísticos. Tesis doctoral inédita. UAM, Madrid.

y MoRALES, A. (1985): «Informe sobre los restos, faunísticos recuperados en el yacimiento del Cerro de Santa Ana (Entrena, Logroño)». Berceo 1: 49-165.

MIRÓ, J.Ma (2002): « Estudio de la fauna de la necrópolis ibérica del «Turo dels dos Pins» (Cabrera de Mar, El Marcéeme, Prov. Barcelona): Un ejemplo de arqueozoología en contextos funerarios». Archaeofauna, 1: 157-169.

Morales, A. y Liesau, C. (1994): Primer estudio sobre la fauna del yacimiento de Capote (Higuera La Real, Badajoz). En: Berrocal-Rangel, L. (ed.):289-297.

1995: «Análisis comparado de las faunas arqueológicas en el valle medio del Duero (prov.Valladolid) durante la Edad del Hierro». en: Delibes, G. et al. (eds): 455-514.

Albertini, D.; Blasco Sancho, F.; Cardoso, J.; Castaños Ugarte, P.; Liesau Von LetTow-Vorbeck, C.; Montero Ponseti, S.; Nadal Lorenzo, J.; Nicolas Perez, E.; Perez RiPOLl, M.; Pino URIA, B. y RiQuelme CANTAL, J.A. (1998): «A preliminary catalogue of Holocene equids from the Iberian Peninsula». International Union of Prehistoric and Protohistoric Sciences. Workshops- 6. Tome, $1: 65-82$

Moure, A. (Ed.)(1992): Elefantes, ciervos y ovicaprinos. Universidad de Cantabria.

MusiL, R. (2000): «Domestication of wolves in Central European Magdalenian sites». En: Crockford, S. J. (Ed): 21-28.

Nores, C. y LiesaU, C. (1992): «La Zoología Histórica como complemento de la Arqueozoología. El caso del Zebro». Archaeofauna, 1: 61-71.

OLSEN, S. (1998): «Horse hunting strategies in the Paleolithic». International Union of Prehistoric and Protohistoric Sciences. Workshops- 6. Tome,1:37-44.

PETERS, J. y VON DEN DRIESCH, A. (1990):Archäozoologische Untersuchungen der Tierreste aus der Kupferzeitlichen Siedlung von Los Millares (Prov. Almería): Studien über frühe Tierknochenfunde von der Iberischen Halbinsel, 12. München: 51-109

PÉREZ RIPOLL, M. 1977: Los mamíferos del yacimiento Musteriense de Cova Negra (Játiva, Valencia). SIP, 53.

PIgGot, S. (1983): The Earliest wheeled Transport: From the Atlantic Coast to the Caspian Sea. Thames and Hudson, Londres.

Quesada Sanz, F. y Zamora Merchan, M. (2003): El caballo en la Antigua Iberia. RAH y UAM. Madrid.

Riquelme Cantal, J. A. (1995): Presencia del caballo Equus caballus en el Sur de la Península Ibérica desde el Paleolítico Inferior hasta la Edad Moderna. En: VVAA: Al Andalus y el Caballo. Sierra Nevada. Barcelona: 17-29. 
ROES (1960): «Horn cheekpieces». The Antiquaries Journal, XI:68-72.

Ruiz-Galvez (1991): «La economía celtibérica» En: Los Celtas en la Península Ibérica (Revista de Arqueología):76-81.

SÁNCHEZ Moreno, E. (1995): "El caballo entre los pueblos prerromanos de la Meseta Occidental”. Studia Historica, 13-14: 207-229.

SAnZ, J. y Morales, A. (2000): Los restos faunísticos. En: Contreras F. (coord.): 223-235.

SANZ MingueZ, C. (1990): «Rituales funerarios en la necrópolis celtibérica de Las Ruedas, Padilla de Duero (Valladolid). En: Burillo, F. (Coord.): Necrópolis celtibéricas. II Simposio sobre los celtíberos. Institución Fernando el Católico, Zaragoza: 159-169.

SCHIBLER, J.; SEDLMEIER, J. y SPYCHER H. (Eds.) (1990): Festschrift für Hans. R. Stampfli. Beiträge zur Archäozoologie Archäologie, Geologie und Paläontologie. Helbig y Lichtenhahn, Basilea.

SCHUBART, H. (2001): Die Stratigraphie auf der Kuppe und am Osthang des Siedlungshügels von Fuente Álamo : Schicht- und Phasengliederung. En: Schubart, H., Pingel V. Arteaga, O (Eds.): Fuente Álamo, Teil 1. Philipp von Zabern, Mainz.

$31: \overline{154-168 .}$

Y RISCH (1990): Frühbronzezeitliche Stelen von Fuente Álamo. Madrider Mitteilungen,

SCHÜLE, W. (1969a): «Glockenbecher und Hauspferde». En: Boessneck (Ed.): Archäologie und Biologie, Forschungsberichte, 15: 88-93. Berlín.

SCHÜLE, W. (1969b): Die Meseta-Kulturen der Iberischen Halbinsel. Madrider Forschungen, 3.

SChUlten, A. 1920: Hispania. (Geografia, Etnología, Historia.) Barcelona.

SERPELL, J. (Ed.) (1995): The domestic dog: its evolution, behavior, and interactions with people. Cambridge University Press. Cambridge.

SiRET, E. y L. (1890): Las Primeras Edades del Metal en el Sudoeste de España. Barcelona.

Sopeña, G. (1987): Dioses, ética y ritos. Aproximaciones para una comprensión de la religiosidad entre los pueblos celtibéricos. Universidad de Zaragoza. Zaragoza.

Sото (1984): «Estudio Paleontológico». Apéndice II. En Jimeno: 323-333.

SpanedDa, L.; LizCANo, R.; CÁmara, J.A. y CONTRERas, F.(2004): «El poblado de Sevilleja y la Edad del Bronce en el valle del Rumblar». En: García Huerta, R. y Morales Hervás, J. (Coord.): 57-85.

Telegin, D. Y. (1986): Dereivka: A settlement and cementery of Copper Age horse beepers in the middle Dnieper. BAR, IS 287: 1-126.

TORRES ORTíz, M. (1999): «Interacción entre fenicios e indígenas en el suroeste peninsular: las prácticas funerarias». II Congreso de Arqueología Peninsular, vol. 2. Alcalá de Henares, Fundación Rei Afonso Henriques: 191-219.

UERPMANN, H-P. (1976): «Equus (Equus) caballus und Equus (Asinus) hydruntinus im Postpleistozän der Iberischen Halbinsel (Perissodactyla, Mammalia)». Säugetierkundliche Mitteilungen, 24 Jhg.3, 206-218.

(1990): «Die Domestikation des Pferdes im Chalkolithikum West- und Mitteleuropas». Madrider Mitteilungen, 31: 109-153.

(1995): «Domestication of the horse: when, where and why»? En: Le cheval et les autres équidés : Aspects de l'Histoire de leur insertion dans les activités humaines. Colloques d'Histoire des Connaissances Zoologiques. Université de Liège, 6 : 15-29.

WeBBer, T. (2003): Bocas y embocaduras. Editorial Hispano Europea. Barcelona.

ZIEGLER, R. (1990): «Tierreste aus der Prähistorischen Siedlung von Los Castillejos bei Montefrío (Prov. Granada)»: Studien über frühe Tierknochenfunde von der Iberischen Halbinsel, 12. München: 1-46.

VVAA (1995): Al Andalus y el caballo. Ed. Sierra Nevada. Madrid- Barcelona. 